\title{
Transition from Forward Smoldering to Flaming in Small Polyurethane Foam Samples
}

\author{
AMNON BAR-ILAN \\ Department of Mechanical Engineering \\ University of California, Berkeley \\ Berkeley, CA 94720
}

\begin{abstract}
Experimental observations are presented of the effect of the flow velocity and oxygen concentration, and of a thermal radiant flux, on the transition from smoldering to flaming in forward smoldering of small samples of polyurethane foam with a gas/solid interface. Because small polyurethane foam samples were studied, the smolder propagation and the transition to flaming had to be assisted by reducing the heat losses to the surroundings and increasing the oxygen concentration. The experiments are conducted with small parallelepiped samples vertically placed in a wind tunnel. Three of the sample lateralsides are maintained at elevated temperature and the fourth side is exposed to an upward flow and to a radiant flux. It is found that decreasing the flow velocity and increasing its oxygen concentration, and/or increasing the radiant flux enhances the transition to flaming, and reduces the delay time to transition. Limiting external ambient conditions for the transition to flaming are reported for the present experimental set-up. The results indicate that transition to flaming occurs in the char left behind by the smolder reaction, as evidenced by ultrasound probing of the sample interior, and it has the characteristics of a gas-phase ignition induced by the smolder reaction. A simplified scale analysis is presented, which shows that the transition can be treated as a gas-phase ignition process.
\end{abstract}

KEYWORDS: smoldering, transition to flaming, polyurethane foam, ultrasound

\section{NOMENCLATURE}

\begin{tabular}{|c|c|c|c|}
\hline$A$ & Area $\left[\mathrm{m}^{2}\right]$ & \multicolumn{2}{|c|}{ Subscripts } \\
\hline$c$ & Specific heat $[\mathrm{kJ} / \mathrm{kg}-\mathrm{K}]$ & $a$ & Ambient \\
\hline$d$ & Unburned foam thickness [m] & C & Cross-sectional \\
\hline$h$ & $\begin{array}{l}\text { Convective heat transfer coefficient } \\
{\left[\mathrm{W} / \mathrm{m}^{2}-\mathrm{K}\right]}\end{array}$ & c & Critical \\
\hline$k$ & Thermal conductivity [W/m-K] & free & Free surface \\
\hline$L$ & Length [m] & $g$ & Gas \\
\hline$Q$ & Heat $[\mathrm{kJ} / \mathrm{kg}]$ & $\vec{i}$ & Internal \\
\hline$\dot{Q}^{\prime \prime}$ & Heat flux $\left[\mathrm{W} / \mathrm{m}^{2}\right]$ & $\mathrm{ig}$ & Igniter \\
\hline$T$ & Temperature $[\mathrm{K}]$ & $L$ & Lateral \\
\hline$U$ & $\begin{array}{l}\text { Overall heat transfer coefficient } \\
{\left[\mathrm{W} / \mathrm{m}^{2}-\mathrm{K}\right]}\end{array}$ & loss & Heat loss \\
\hline$u$ & Velocity [m/s] & $P$ & Pyrolysis \\
\hline & Mole fraction & $\mathrm{rad}$ & Radiative \\
\hline Greek & & $s$ & Solid \\
\hline$\delta$ & Smolder reaction zone thickness [m] & side & Side Wall \\
\hline$\phi$ & Porosity & sml & Smolder \\
\hline$\rho$ & Density $\left[\mathrm{kg} / \mathrm{m}^{3}\right]$ & $w$ & Wall \\
\hline
\end{tabular}




\section{INTRODUCTION}

The transition from smoldering to flaming is of interest both as a fundamental combustion problem and as a serious fire risk. It encompasses phenomena related to the ignition of a homogeneous gas phase reaction (flaming) that is induced by a heterogeneous surface reaction (smolder) that acts both as the source of gaseous fuel (pyrolyzate, CO, etc.) and the source of heat to initiate the homogeneous reaction [1-4]. That it is a fire hazard is confirmed by the fact that more than $40 \%$ of United States residential fire deaths can be attributed to smoldering [5]. The transition from smoldering to flaming is also of concern in the space flight program; to date there have been a few minor incidents of overheated and charred cables and electrical components reported on Space Shuttle flights $[1,6]$ and significant smolder-related incidents aboard the Russian space station Mir [7]. With the ongoing establishment of the International Space Station and the planning of other long-term space missions, there is an added need to study smoldering and its transition to flaming in microgravity in order to prevent and minimize the effects of a smolder-initiated fire.

The configuration in which transition to flaming is more likely to occur is forward smolder, where the oxidizer flows in the same direction as that of smolder propagation $[8,9]$. Thus, the oxidizer reaches the reaction zone after passing through the hot char left behind by the propagating smolder reaction, and the transition to flaming may occur by vigorous oxidation of this char. In this case the transport processes at the interface may play an important role in the process [3,4]. The flow of oxidizer at the solid/gas interface can enhance or deter the smolder process, depending on the balance between the oxygen supply to the reaction, and convective heat loss from the reaction.

While considerable work has been conducted to understand the smoldering combustion of porous fuels, there has been considerably less research conducted on the transition from smoldering to flaming. Prior work in transition from smoldering to flaming considered cellulosic materials or polyurethane foam samples of different sizes and with different oxygen concentrations [3,4,10-14]. Most of the experiments were conducted with a solid/ gas interface, in a horizontal arrangement for loose materials, or vertical for materials that maintained their structure during smolder. The flows were both naturally induced or forced. A common observation of these works is that for the transition from smoldering to flaming to occur the fuel samples have to be fairly large, or the process must be assisted by increasing the oxygen concentration of the oxidizer flow and/or external heating. The present work studies the effects of the heat loss reduction and of increasing the oxidizer flow oxygen concentration on the smolder propagation and its transition to flaming. The work has also demonstrated that both can occur with relatively small fuel samples if the external ambient conditions are appropriate.

\section{EXPERIMENT}

\section{Experiment Concept and Protocol}

The experimental configuration is similar to that employed by Tse et al. [4] i.e., threedimensional forward smolder with a solid/gas interface. The foam sample is a verticallyoriented parallelepiped insulated on three of its surfaces and with the fourth, free surface, exposed to an upward forced convective oxidizer flow parallel to the surface. Smolder ignition is induced at the bottom of the sample and smolder propagates upward in the 
same direction as the oxidizer flow (buoyant and forced), i.e., forward smolder. A schematic of the experiment is shown in Fig. 1.

FRONT VIEW

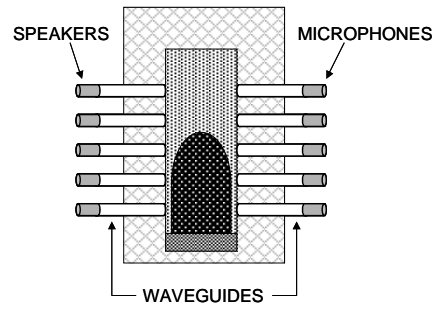

SIDE VIEW

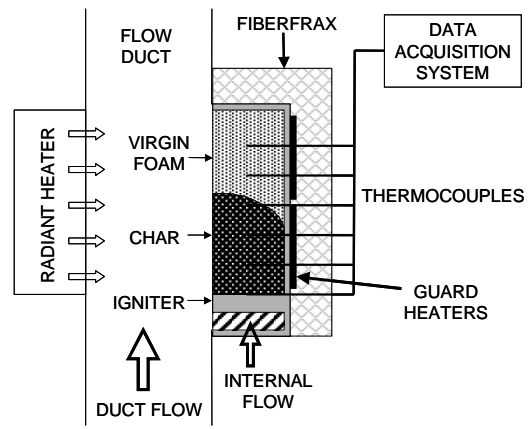

Fig. 1. Schematic of the experimental apparatus.

As indicated above, the sample is limited in size to dimensions that are too small for smolder to self propagate even in microgravity [15] and for transition to flaming to occur [12]. Smolder is a weak reaction that is very sensitive to external heat losses, which increase as the sample size is reduced and can prevent smolder propagation. A simplified analysis of smolder propagation $[9,16]$ helps to illustrate this aspect of the problem. Smolder often occurs under oxygen-limited conditions [9], and consequently the rate of heat release from the smolder reaction is directly proportional to the oxidizer mass-flux. The heat released by the reaction is in turn partially transferred ahead of the reaction and partially lost to the surrounding environment. Under these conditions, the smolder propagation velocity is given by Eq. 1:

$$
u_{s m l}=\frac{y_{O 2} \rho_{g} u_{i} Q_{s m l}-\dot{Q}_{\text {loss }}^{\prime \prime} A_{L} / A_{c}+\dot{Q}_{i g}^{\prime \prime}}{\left[(1-\phi) \rho_{s} c_{s}+\phi \rho_{g} c_{p, g}\right]\left(T_{s m l}-T_{a}\right)-(1-\phi) \rho_{s} Q_{P}+y_{O 2} \rho_{g} Q_{s m l}}
$$

It is seen from the above equation that the influence of the heat losses on the smolder propagation is proportional to the ratio of the peripheral area of the smolder reaction zone to the smolder reaction surface area. For a sample of square cross-section of side $L$ [m] and a given smolder reaction zone axial thickness $\delta$ [m], this ratio is $A_{L} / A_{C}=4 \delta / L$. Thus, as the sample size $L$ is made smaller the effect of the heat losses increases until smolder propagation cannot occur. Using this equation and Eq. 1, and assuming the heat from the igniter is negligible (self-smolder), it is possible to determine a critical sample size below which self-sustained smolder will not occur. This critical size can be expressed as:

$$
L_{c}=\frac{4 \delta}{Q_{s m l}} \frac{U_{\text {loss }}\left(T_{s m l}-T_{w}\right)}{y_{O 2} \rho_{g} u_{i}}
$$

where $U_{\text {loss }}$ is the overall heat transfer coefficient expressed relative to the temperature gradient between the smolder zone and the sample wall [17]. Thus for a sample size below this critical size, to sustain smolder, the heat losses must be reduced or the heat generated by the smolder reaction increased, or both. The former can be accomplished by 
insulating the sample (decreasing $U_{\text {loss }}$ ) or increasing the wall temperature $T_{w}$, and the latter by increasing the oxygen concentration of the oxidizer flow.

Controlling the wall temperature with guard heaters on the holder sides was found to be the most effective approach for limiting the heat losses. In order to avoid significant thermal decomposition by pyrolysis, the sample-holder walls are maintained above $200^{\circ} \mathrm{C}$. At this temperature, the foam degradation in isothermal thermogravimetric experiments [18] is below $5 \%$ but rapidly increases if temperature rises (i.e., at $220^{\circ} \mathrm{C}$ the foam conversion is 20\%). Also, the free sample surface was exposed to an external radiant flux kept below $10 \mathrm{~kW} / \mathrm{m}^{2}$, to avoid a smolder initiated by the radiant flux alone. The sample still loses heat at the free surface by convection to the oxidizer flow, whose velocity becomes a parameter of the problem.

To enhance the heat generated by the reaction, the transition to flaming experiments are conducted with oxidizer flows at oxygen concentrations above that for air, which also becomes a parameter of the problem. To ensure a transition process that is solely generated by the smolder reaction and not assisted by the igniter, smolder is initiated and allowed to propagate beyond the igniter influence in air initially. Once self-smolder propagation is established, the igniter is turned off, allowed to cool to temperatures below $250^{\circ} \mathrm{C}$ and the internal and external oxidizer flows switched to the nominal oxygen concentration for the experiment. Transition to flaming is considered not to occur if smolder propagates through the whole sample without transition, or if smolder propagation does not occur beyond the region influenced by the igniter.

\section{Experimental Apparatus}

The experiments are conducted in a small vertically oriented aluminum flow duct (Fig. 1), $380 \mathrm{~mm}$ long and with a cross-sectional area of $135 \mathrm{~mm}$ by $80 \mathrm{~mm}$. One wall of the flow duct consists of a pane of borosilicate glass for optical access. The opposite wall includes a calcium fluoride window $(25 \mathrm{~mm} \times 100 \mathrm{~mm})$ for infrared imaging. The oxidizer flow entering the test section of the flow duct first passes through a settling chamber and a converging nozzle.

The sample holder is located $120 \mathrm{~mm}$ from the inlet to the flow duct and vertically oriented such that the front face of the fuel sample is flush with the interior wall of the flow duct. The sample holder is constructed of thin-walled $(0.75 \mathrm{~mm})$ brass sheets insulated with Fiberfrax, with a central cavity to contain the fuel sample (50 $\mathrm{mm} \mathrm{x}$ $50 \mathrm{~mm}$ cross section and $125 \mathrm{~mm}$ long), and the igniter holder assembly. The outer surfaces of the back and side walls of the sample holder each have an independently controlled guard heater.

An infrared radiant heater is mounted opposite the sample holder in the vertical wall of the flow duct to counter heat losses from the free surface of the fuel sample with a radiant flux perpendicular to the sample surface. The radiant heat flux from the heater was measured using air-cooled radiometers placed in the fuel sample.

In order to initiate the smolder reaction, the front face of the sample is in contact with an electrically heated ceramic honeycomb igniter of area $50 \mathrm{~mm}$ by $50 \mathrm{~mm}$. The bottom face of the igniter is insulated with a layer of Fiberfrax of thickness $15 \mathrm{~mm}$. During the tests, there is a forced flow of oxidizer through the Fiberfrax and the igniter, and into the fuel sample at a flow rate of $13.4 \mathrm{cc} / \mathrm{s}$, which was determined to be the optimal internal flow rate for smolder ignition and propagation from previous testing. 
The duct oxidizer flow is controlled using two identical sets of critical flow nozzles. Duct oxidizer flow velocities are uniform over the cross section of the flow duct, with minimal boundary layer growth. The internal oxidizer flow through the igniter is controlled using mass flow controllers.

In all testing, the fuel samples were open-celled, non-flame-retardant, flexible polyurethane foam. The fuel properties are listed in [17]. Five type-K thermocouples are located along the centerline of the sample at distances from the igniter/fuel interface of: $0 \mathrm{~mm}, 20 \mathrm{~mm}, 41 \mathrm{~mm}, 62 \mathrm{~mm}$, and $94 \mathrm{~mm}$. The igniter thermocouple is a $0.14 \mathrm{~mm}$ diameter bare-wire thermocouple, while the other four are $0.84 \mathrm{~mm}$ diameter sheathed grounded thermocouple probes, inserted through the back of the sample. An ultrasound probing system is implemented as well, using pairs of ultrasonic speakers and microphones located at the same axial positions as the thermocouples. The ultrasound system, including the principle of operation, is described in detail in [19]. In addition, an infrared camera (FLIR Systems Model SC1000) monitors the surface temperature of the foam at an oblique angle of approximately $45^{\circ}$, and views the sample through the calcium fluoride window. Because the emissivity of the surface of the fuel sample is unknown and varies due to the changing molecular structure of the surface caused by the smolder reaction, all surface temperatures reported by the infrared camera are equivalent blackbody temperatures. A video camera views the sample through the borosilicate window.

\section{RESULTS}

\section{Thermocouple, Video and Infrared Camera Results}

Characteristic temperature time histories are shown in Fig. 2 comparing two tests with and without a transition to flame. The temperatures of Fig. 2a are typical of those observed in forward smolder [9], although once the flow is switched from air to the nominal oxygen concentration there is an increase in temperature upstream of the
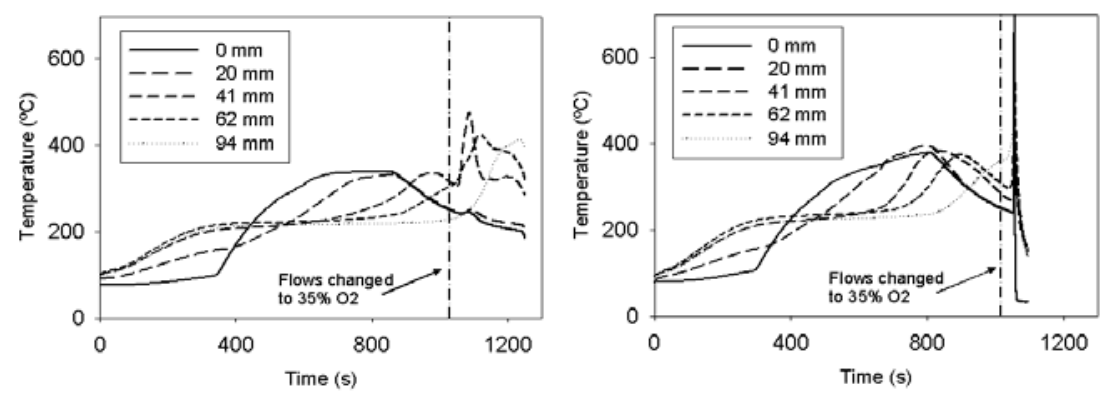

Fig. 2. Sample thermocouple histories from a test that did not transition (left) and a test that did transition (right).

smolder reaction indicating an enhancement of the char oxidation reaction. Following the temperature histories in Fig. $2 \mathrm{~b}$ it is seen that the temperatures of the thermocouples located at $41 \mathrm{~mm}$ and $62 \mathrm{~mm}$ from the igniter increase steadily and reach a peak of approximately $382^{\circ} \mathrm{C}$, indicating the arrival of the smolder front at the thermocouple location. The temperature of the thermocouple located at $94 \mathrm{~mm}$ increases steadily indicating the approach of the smolder reaction. At 1019 s, the internal and duct flows are 
enriched to the nominal oxygen concentration, and at approximately $1035 \mathrm{~s}$ there occurs a noticeable change in the slope of the temperature history of the thermocouple at $94 \mathrm{~mm}$. The thermocouples at $62 \mathrm{~mm}$ and $41 \mathrm{~mm}$ attain minimum values before increasing sharply. The transition to flame, indicated by the sharp temperature increase of these thermocouples, occurs at approximately $1054 \mathrm{~s}$, which is confirmed by both video and infrared imaging. Enlargement of the temperature histories in the vicinity of the transition to flaming shows the transition occurring at a location between thermocouples at $41 \mathrm{~mm}$ and $62 \mathrm{~mm}$ and foam burning rapidly propagating downstream and upstream along the foam.

In Fig. 3, video and infrared camera images are presented of a characteristic example of the transition from smoldering to flaming. The first two video images show that the smolder reaction has been ignited and progressed approximately $95 \mathrm{~mm}$ through the sample height. The char structure on the free surface shows that the smolder reaction does not spread to the edges of the sample, due to heat losses to the holder walls. Once the oxidizer flow is switched to the nominal oxygen concentration an intensification of the reaction is observed, as shown in Fig. 3a by comparison of the second, third, and fourth images in the sequence. The reaction also spreads transversely toward the walls indicating that the stronger reaction helps in overcoming the heat losses to the holder walls. Simultaneously, the top portion of the char on the fuel sample surface is burned away, opening a large hole in the char on the surface. The fifth image clearly shows a flame protruding into the duct from the upper half of the sample. It has been observed that the flame rapidly spreads upstream from the transition, towards the igniter, and engulfs the sample.

The infrared images (Fig. 3b) show that the smolder reaction has propagated away from the igniter and that the lower half of the sample has cooled. This is consistent with other smolder tests $[3,4,9]$ and is due to heat losses to the surrounding. The second, third, and fourth infrared images correspond to the opening of a large hole on the sample surface as seen in the video imaging. The high temperatures in the char, shown in white, exceed the operating range of the camera. The fifth image clearly shows a flame protruding into the duct from the upper half of the sample.

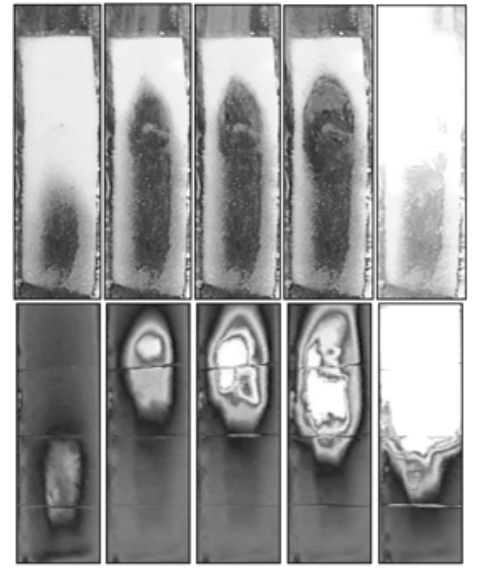

Fig. 3. (Top) video camera images of the transition to flame and (bottom) infrared images of the transition to flame. 


\section{Ultrasound Probing Results}

The results of ultrasound probing of the smolder propagation, and the subsequent transition to flame are presented for a sample test in Fig. 4 . The test conditions are 0.40 oxygen mole fraction, $8.0 \mathrm{~kW} / \mathrm{m}^{2}$ radiant heat flux, and $0.25 \mathrm{~m} / \mathrm{s}$ duct flow.

As can be seen from Fig. 4, the ultrasound probing is able to capture the increase in permeability associated with the passage of the smolder front by the ultrasonic transducer pairs. The increase in permeability is steep, and typically changes the output signal by a factor of 3-4, which is sufficient to use the ultrasound system as a second means of verifying the smolder front position during a test. As can be seen, the increase in permeability once the transition happens is extremely rapid and results in a permeability change of one order of magnitude or greater. This is indicative of the formation of large voids in the char structure which increase the local line-of-sight average permeability.

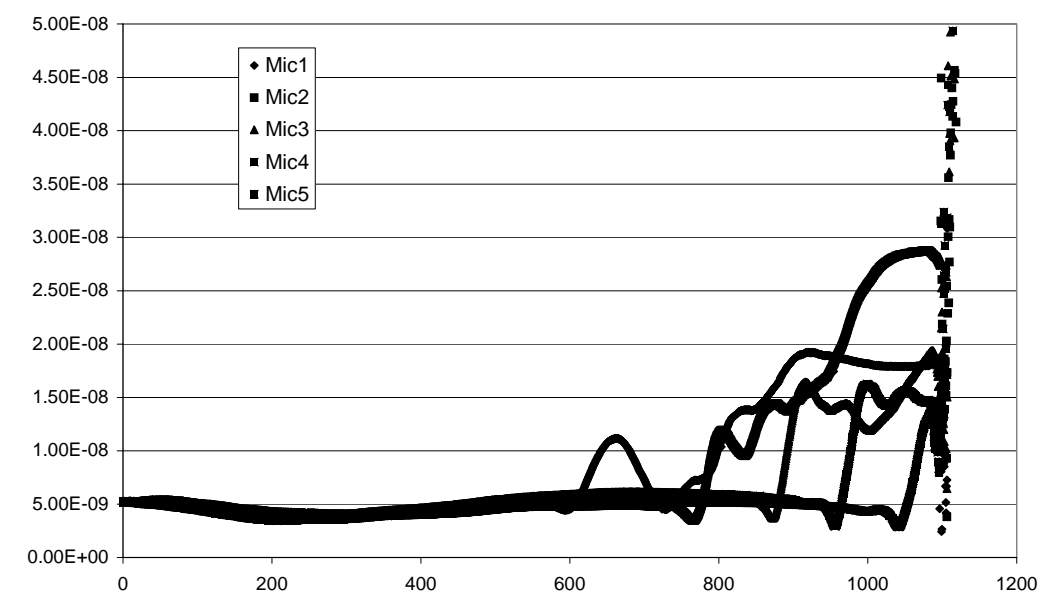

Fig. 4. Sample permeability history from a test that transitioned to flame.

\section{Effect of External Flow Velocity and Oxygen Mole Fraction}

A set of tests was run varying the duct flow velocity and oxygen mole fraction of the internal and duct flows, while holding the heat flux constant at $7.25 \mathrm{~kW} / \mathrm{m}^{2}$ to determine the conditions under which transition from smoldering to flaming occurs. The results of these tests are shown in Table 1. Transition tests are marked with the time delay between the flow oxygen enrichment and the transition to flaming, and failed transition tests are marked with an "N." Tests for which the smolder reaction did not self-propagate are marked with an " $\mathrm{N}^{*}$." The flow velocity reported is that of the forced flow as determined with cold samples. However, since as the sample heats up an upward natural convection flow is generated that adds to the forced flow, the actual flow velocity near the fuel surface is larger than that reported, particularly at low flow velocities. As can be seen from Table 1 transition to flaming was not observed below 35\% oxygen concentration. The tests run with $35 \%$ oxygen produced transition to flaming at a forced flow of $0.25 \mathrm{~m} / \mathrm{s}$, but not at $0.5 \mathrm{~m} / \mathrm{s}$. At $37.5 \%$ and $40 \%$ oxygen, transition to flaming was observed for forced flow velocities equal to or less than $1.5 \mathrm{~m} / \mathrm{s}$. At $2 \mathrm{~m} / \mathrm{s}$ smolder did not self- propagate and transition to flaming did not occur. The results appear to indicate that as the flow velocity increases the time delay to transition also increases. The results also 
appear to indicate that as the oxygen mole fraction increases, the time delay to transition decreases.

Table 1. Effect of duct flow velocity and oxygen fraction on transition to flaming.

\begin{tabular}{l|lllll}
\multirow{2}{*}{$\begin{array}{c}\text { Oxygen Mole } \\
\text { Fraction }\end{array}$} & \multicolumn{5}{|c}{ Duct Flow Velocity [m/s] } \\
0.30 & $\mathbf{0 . 2 5}$ & $\mathbf{0 . 5}$ & $\mathbf{1 . 0}$ & $\mathbf{1 . 5}$ & $\mathbf{2 . 0}$ \\
\cline { 2 - 6 } 0.325 & $\mathrm{~N}$ & $\mathrm{~N}$ & & & \\
0.35 & $\mathrm{~N}$ & $\mathrm{~N}$ & & & \\
0.375 & $32 \mathrm{~s}$ & $\mathrm{~N}$ & $\mathrm{~N}$ & $\mathrm{~N}$ & \\
0.40 & $31 \mathrm{~s}$ & $32 \mathrm{~s}$ & $34 \mathrm{~s}$ & $41 \mathrm{~s}$ & $\mathrm{~N}^{*}$ \\
& $29 \mathrm{~s}$ & $24 \mathrm{~s}$ & $27 \mathrm{~s}$ & $40 \mathrm{~s}$ & $\mathrm{~N}^{*}$
\end{tabular}

\section{Effect of External Heat Flux}

Tests varying the external heat flux were conducted with duct flow velocities of $0.25,0.5$ and 1.0 and $1.5 \mathrm{~m} / \mathrm{s}$, and an oxygen mole fraction of 0.35 . The nominal radiant heat fluxes tested in this series were 7.25, 8.00, $8.75 \mathrm{~kW} / \mathrm{m}^{2}$. As shown in Table 2, transition to flame was observed for all three heat fluxes at a forced flow velocity of $0.25 \mathrm{~m} / \mathrm{s}$. In the case of 0.5 and $1.0 \mathrm{~m} / \mathrm{s}$ duct flow velocities, no transition to flame was observed for a radiant heat flux of $7.25 \mathrm{~kW} / \mathrm{m}^{2}$ but transition to flame was observed at 8.00 and $8.75 \mathrm{~kW} / \mathrm{m}^{2}$. The time delay for transition decreases as the radiant flux is increased.

Table 2. Effect of external radiant heat flux on transition to flaming.

\begin{tabular}{l|llll} 
Heat Flux & \multicolumn{4}{|c}{ Duct Flow Velocity $[\mathrm{m} / \mathrm{s}]$} \\
{$\left[\mathrm{kW} / \mathrm{m}^{2}\right]$} & 0.25 & 0.5 & 1.0 & 1.5 \\
\cline { 2 - 5 } 7.25 & $32 \mathrm{~s}$ & $\mathrm{~N}$ & $\mathrm{~N}$ & $\mathrm{~N}$ \\
8.00 & $27 \mathrm{~s}$ & $38 \mathrm{~s}$ & $35 \mathrm{~s}$ & $\mathrm{~N}$ \\
8.75 & $14 \mathrm{~s}$ & $34 \mathrm{~s}$ & $31 \mathrm{~s}$ & $34 \mathrm{~s}$
\end{tabular}

\section{DISCUSSION}

By studying the detailed temperature history depicted in Fig. 2b, it is observed that the transition to flaming occurs somewhere in the vicinity of the thermocouples at $62 \mathrm{~mm}$ and $41 \mathrm{~mm}$, since they are the first thermocouples to sharply increase in temperature. The fact that both thermocouples start to increase rapidly at almost the same time (1054.5 s) suggests that the transition occurs somewhere between these two thermocouples. At the time of transition, the temperature of the thermocouple at $94 \mathrm{~mm}$ is $446^{\circ} \mathrm{C}$, indicating that the smolder front has already passed this location. These findings are consistent with those of Tse et al. [4], which reported that the transition to flaming occurred in the char behind the smolder front. This is further confirmed by examination of the infrared imaging sequence in Fig. 3b. In the third image in the sequence, it can be clearly seen that the char upstream of the smolder front exhibits 
higher temperatures than at any other location in the fuel sample at that time. The fourth image, just prior to the transition, shows that this region of high temperature char spreads counter to the flow direction while the smolder reaction continues to move in the flow direction.

Table 1 and Table 2 show a demarcation between the regions of transition and no transition, which is in qualitative agreement with Eq. 2. As the overall heat transfer coefficient for the heat losses increases due to convective cooling from the increased duct flow or lower radiant heat flux, the oxygen concentration must be increased for transition to occur. Thus the results presented above support the conclusion that the transition from smolder to flaming is a type of spontaneous gas phase ignition where the smolder reaction acts both as source of fuel and of heat for the reaction. They also indicate that in order for the transition to occur the heat generated by the reaction has to overcome the heat losses to the surrounding environment. For example, it is expected that increasing the oxidizer flow velocity can enhance the reaction in the char by providing increased oxygen, but can also convectively cool the reaction. The results of Tables 1 and 2 indicate that the latter is dominant in the present experiments since transition does not occur at the higher velocities and the delay to transition increases as the flow velocity is increased. Similarly, it is expected that increasing the external heat fluxes will enhance the tendency to transition to flaming since the heat losses are reduced, as observed in the experiments. As per the effect of the oxidizer flow oxygen concentration, an increase in oxygen mole fraction for a constant radiant heat flux and constant duct flow velocity, will increase the reaction rate of the secondary char oxidation reaction and of the gas phase reaction, thus increasing their heat release rate. Thus it is expected that at a sufficient increase in oxygen concentration the heat generation will overcome the heat losses, which in turn will lead to the transition to flame. From the data presented in Tables 1 and 2 a threshold oxygen mole fraction between 0.325 and 0.35 has been identified below which the transition to flaming does not occur for the present experimental protocol and natural convection conditions.

For an oxygen mole fraction of 0.35 , and duct flow velocities of $0.5 \mathrm{~m} / \mathrm{s}$ and $1 \mathrm{~m} / \mathrm{s}$, there is a threshold radiant heat flux between 7.25 and $8.00 \mathrm{~kW} / \mathrm{m}^{2}$ below which a transition to flame is not observed. In addition, for an oxygen mole fraction of 0.35 and a duct flow velocity of $1.5 \mathrm{~m} / \mathrm{s}$, there is a threshold radiant heat flux between 8.00 and $8.75 \mathrm{~kW} / \mathrm{m}^{2}$ below which a transition to flame is not observed. Thus it appears that below these threshold heat fluxes, the radiant heat flux cannot overcome the heat losses and therefore transition to flame does not occur.

It is possible to analyze this demarcation region between the transition and no transition regimes by applying a simplified scaling analysis to the problem. An energy balance is applied to the smolder front in Eq. 3:

$Q_{\text {sml }} y_{O_{2}} \rho_{g} u_{i} A_{c}=\left(\dot{Q}_{\text {free }}^{\prime \prime}+3 \dot{Q}_{\text {side }}^{\prime \prime}-\dot{Q}_{\text {rad }}^{\prime \prime}\right) A_{L}$

where,

$\dot{Q}_{\text {free }}^{\prime \prime}=h_{\text {free }}\left(T_{s}-T_{0}\right) \approx 2.5 \sqrt{u}$ 
$\dot{Q}_{\text {side }}^{\prime \prime}=k_{s} \frac{\left(T_{s}-T_{w}\right)}{d} \approx 5.6$

In this analysis, $h_{\text {free }}$ in Eq. 3 is the heat transfer coefficient due to a boundary layer flow over a flat plate, ignoring the porosity of the foam. Values for $T_{s}, T_{0}$ and $d$ are obtained from the experiments. If the left hand term is slightly greater than the right hand term in Eq. 3, there is just sufficient energy to overcome the external heat losses and a thermal runaway will result leading to a transition. Thus the equality in Eq. 3 demarcates the boundary between the transition and no-transition regimes. Combining these three equations leads to an expression relating the external flow velocity, oxygen mole fraction, and external radiant heat flux at the demarcation line:

$u \approx\left(13 y_{O_{2}}+0.4 \dot{Q}_{\text {rad }}^{\prime \prime}-6.7\right)^{2}$

Plotting Eq. 6 with the available experimental data shows good agreement between the data and the predicted demarcation line between the transition and no-transition regimes, as shown in Fig. 5.
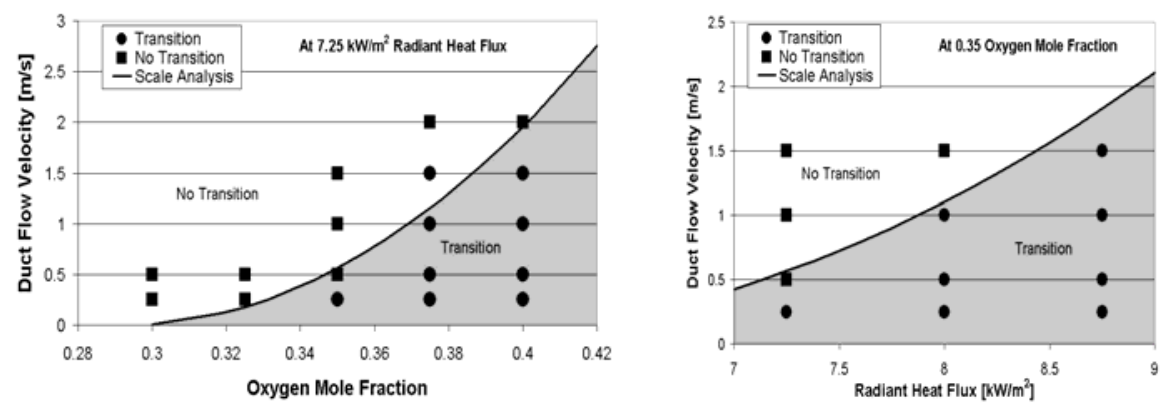

Fig. 5. Scale analysis of transition to flaming, showing predicted demarcation between transition and no-transition regimes and comparison to experimental data.

As can be seen, the agreement between the predicted demarcation between the transition and no-transition regimes, and the experimental data is good. This indicates that the simplified energy balance used in the scale analysis is able to capture the behavior of the transition to flame with respect to oxygen mole fraction, radiant heat flux and duct flow velocity. In addition, this analysis shows that the transition to flame can be seen as a selfheating to ignition process.

\section{CONCLUSIONS}

The presented experiments show strong evidence that a transition from smolder to flaming occurs in the char upstream of the smolder reaction, in agreement with previous observations of the process. A combination of infrared and video imaging, with in-depth thermocouples and ultrasonic probing adequately tracked the progress of the smolder reaction, and captured the transition to flaming event in sufficient detail to determine the approximate location of the transition and the time delay to the transition event. 
It is shown that the transition to flaming is sensitive to the external heat losses, and the heat generated by the secondary char reactions occurring in the char upstream of the smolder reaction. The data shows that increasing the oxygen concentration of the oxidizer flow, reducing the velocity of the external flow, and/or increasing the external radiant flux increases the likelihood of a transition to flaming. These observations support the concept that the transition from smolder to flaming is basically a spontaneous gas phase ignition reaction that is supported by the smolder reaction, which acts both as the source of gaseous fuel (pyrolyzate) and of heat to support the reaction. The transition is more likely to occur when the heat released by both the heterogeneous smolder reaction and the homogeneous gas phase reaction is larger than the heat losses to the surrounding environment. These findings are supported by the observations that the transition occurs in the interior of the char, where it is more likely that the pyrolyzate be present since the smolder reactions are generally oxygen limited, and where the reactions are thermally insulated from the exterior by the char itself. Under these conditions a sudden surge of oxygen, due to openings in the char near the sample surface, or external increases in the oxygen supply, could trigger the onset of the gas phase reaction and consequently the transition to flaming.

\section{REFERENCES}

[1] T'ien, J.S., Shih, H., Jiang, C., Ross, H.D., Miller, F.J., Fernandez-Pello, A.C., Torero, J.L., and Walther, D.C., "Mechanisms of Flame Spread and Smolder Wave Propagation,” Microgravity Combustion: Fire in Free Fall, H.D. Ross Editor, Academic Press, 2001, pp. 299-417.

[2] Drysdale, D., An Introduction to Fire Dynamics, John Wiley and Sons, Chichester, 1985, p. 284-285.

[3] Ohlemiller, T.J., "Smoldering Combustion Propagation Through a Permeable Horizontal Fuel Layer,” Combustion and Flame, 81, pp. 341-353, (1990).

[4] Tse, S.D., Fernandez-Pello, A.C., and Miyasaka, K., "Controlling Mechanisms in the Transition from Smoldering to Flaming of Flexible Polyurethane Foam," Twenty-Sixth Symposium (International) on Combustion, The Combustion Institute, 1996, pp. 1505-1513.

[5] Damant, G.H., "Recent United States Developments in Tests and Materials for the Flammability of Furnishings,” Journal of the Textile Institute, 85, pp. 505525, (1994).

[6] Friedman, R., "Risks and Issues in Fire Safety on the Space Station," NASA Technical Report TM-198906403, Washington, DC, 1993.

[7] Oberg, J., Star-Crossed Orbits, McGraw-Hill, New York, 2002, pp. 102-108.

[8] Ohlemiller, T.J., "Modeling of Smoldering Combustion Propagation,” Progress in Energy and Combustion Science, 11, pp. 277-310, (1985).

[9] Torero, J.L., and Fernandez-Pello, A.C., "Forward Smolder of Polyurethane Foam in a Forced Air Flow," Combustion and Flame, 106, pp. 89-109, (1996).

[10] Palmer, K.N., "Smouldering Combustion in Dusts and Fibrous Materials," Combustion and Flame, 1, pp. 129-154, (1957). 
[11] Ortiz-Molina, M.G., Toong, T.Y., and Garris, C.A., "Smoldering Combustion of Flexible Polyurethane Foams and its Transition to Flaming or Extinguishment," Seventeenth Symposium (International) on Combustion, The Combustion Institute, 1979, pp. 1191-1200.

[12] Rogers, F.E., and Ohlemiller, T.J., "Smolder Characteristics of Flexible Polyurethane Foams," Journal of Fire and Flammability, 11, pp. 32-44, (1980).

[13] Chen, Y., Kauffman, C.W., Sichel, M., Fangrat, J., and Guo, Y., "The Transition from Smoldering to Glowing to Flaming Combustion,” Fall Technical Meeting, Eastern States Section of the Combustion Institute, 1990, p. 68.

[14] Chao, C.Y.H., and Wang, J.H., "Transition from Smoldering to Flaming Combustion of Horizontally Oriented Flexible Polyurethane Foam with Natural Convection," Combustion and Flame, 127, pp. 2252-2264, (2001).

[15] Stocker, D.P., Olson, S.L., Urban, D.L., Torero, J.L., Walther, D.C., and Fernandez-Pello, A.C., "Small-scale Smoldering Combustion Experiments in Microgravity," Twenty-Sixth Symposium (International) on Combustion, The Combustion Institute, 1996, pp. 1361-1368.

[16] Dosanjh, S.S., and Pagni, P.J., "Forced Countercurrent Smoldering Combustion," Proceedings of the 1987 ASME/JSME Thermal Engineering Joint Conference, American Society of Mechanical Engineering/Japan Society of Mechanical Engineering, 1987, pp. 165-173.

[17] Bar-Ilan, A., Rein, G., Walther, D.C., and Fernandez-Pello, A.C., "The Effect of Buoyancy on Opposed Smoldering," Combustion Science and Technology, 176:, pp. 2027-2055, (2004).

[18] Bilbao, R., Mastral, F.J., Ceamanos, J., and Aldea, M.E., "Kinetics of the Thermal Decomposition of Polyurethane Foams in Nitrogen and Air Atmospheres," Journal of Analytical and Applied Pyrolysis, 37, pp. 69-82, (1996).

[19] Putzeys, O., Titus, R., Bar-Ilan, A., Urban, D.L., and Fernandez-Pello, A.C., "Observations of Forward Smoldering and the Transition to Flaming in Small Polyurethane Foam Samples with Ultrasound Probing," Proceedings of the $43^{\text {rd }}$ AIAA Space Sciences Meeting, American Institute of Aeronautics and Astronautics, 2005, pp. 2005-0715. 